
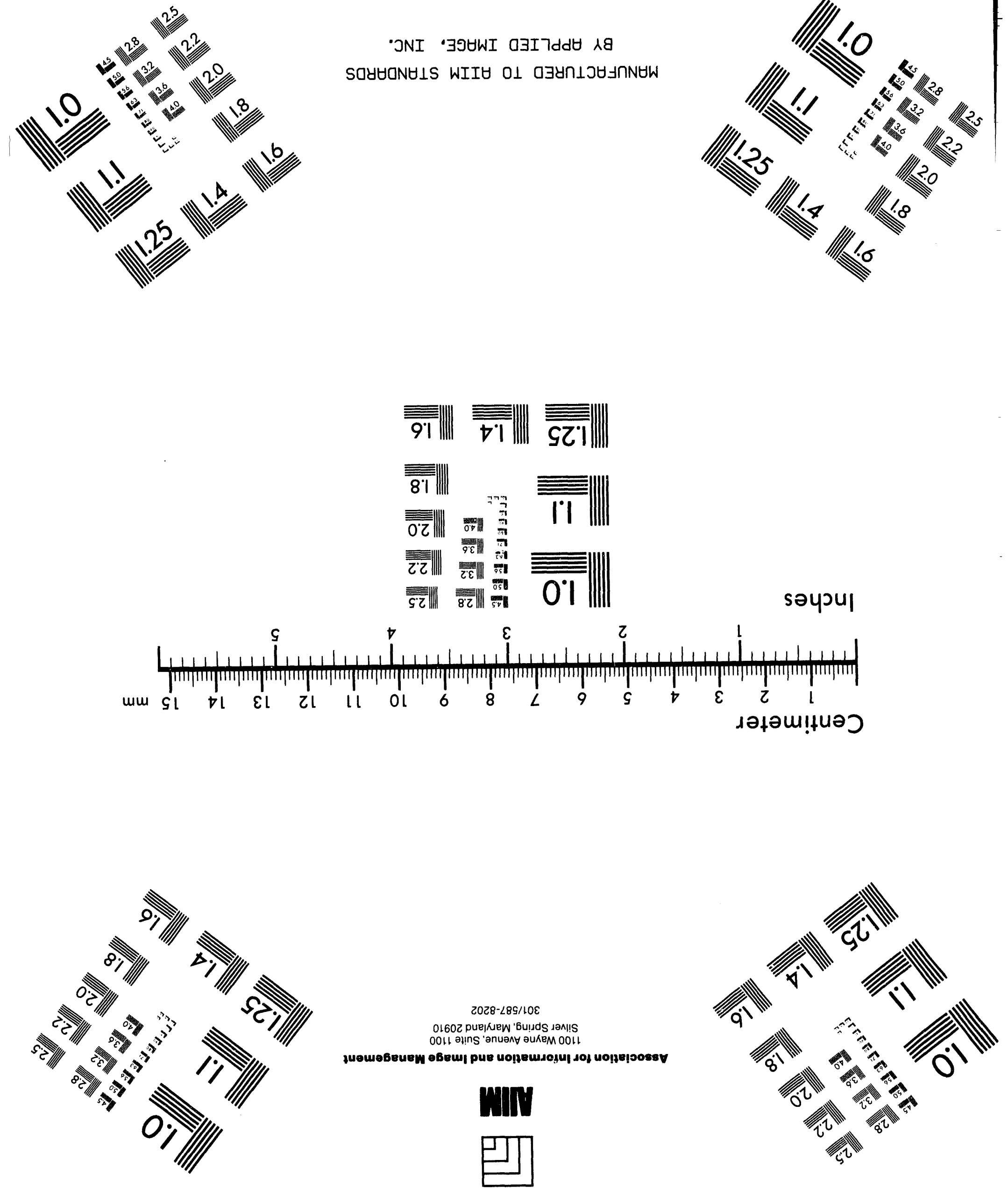

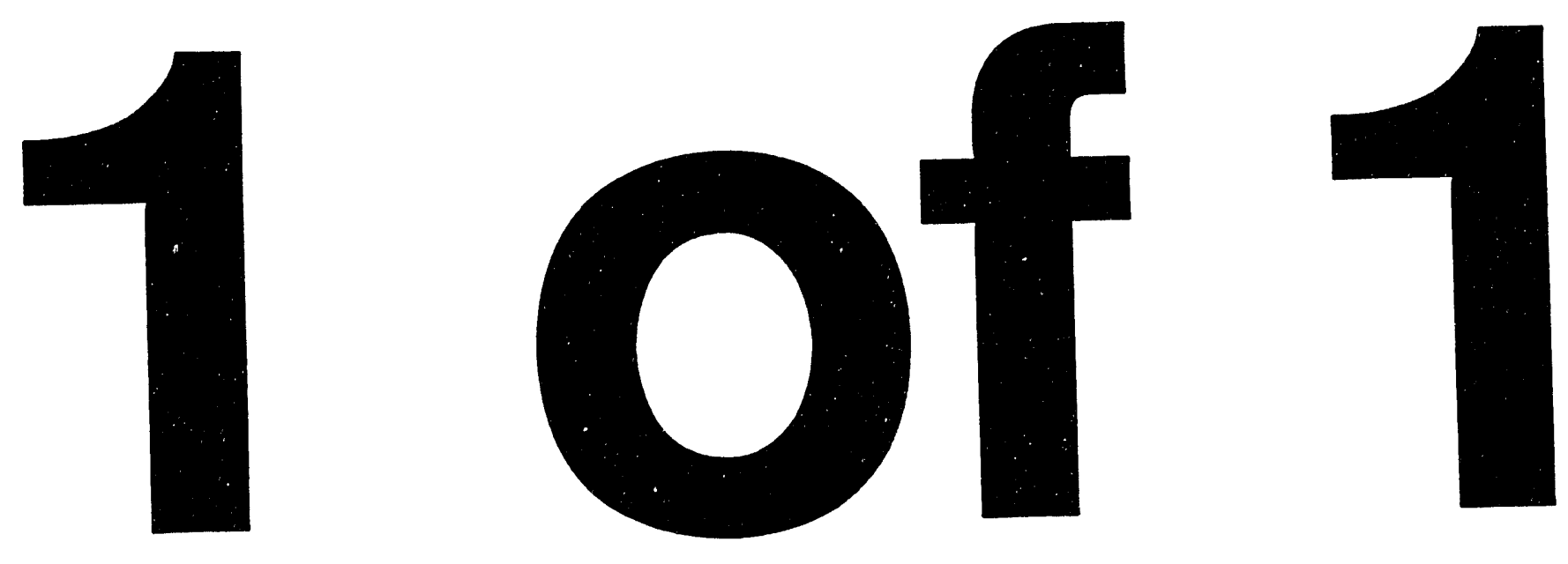


\title{
SHORT CONTACT TIME DIRECT COAL LIQUEFACTION USING A NOVEL BATCH REACTOR
}

Progress Report

$1 / 1 / 94-5 / 15 / 94$

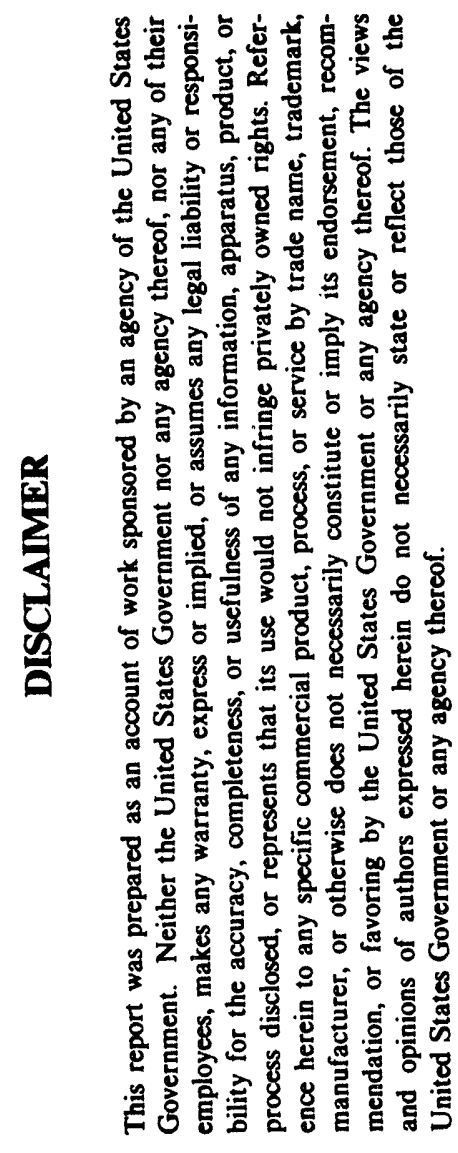

\author{
Michael T.Klein \\ Principal Investigator \\ and \\ William H. Calkins \\ Co-Principal Investigator
}

Center for Catalytic Science and Technology

Department of Chemical Engineering

University of Delaware

Newark, Delaware 19716

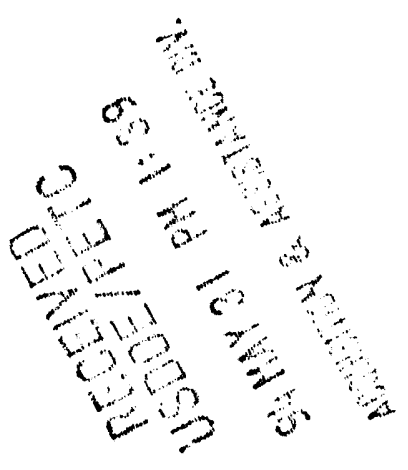

Date Published

May 31, 1994

Contract Number: DE-FG22-93PC93205

Prepared for the Department of Energy 


\section{INTRODUCTION}

The objective for this research is to optimize the design and operation of the bench scale batch reactor (SCTBR) for coal liquefaction at short contact times $(0.01$ to 10 minutes or longer). This reactor is simple enough and low enough in cost to serve as a suitable replacement for the traditional tubing-bomb reactors for many coal liquefaction and other high-pressure, high-temperature reaction studies. The liquefaction of selected Argonne Premium coals and the role of organic oxygen components of the coal and their reaction pathways at very low conversions are being investigated.

\subsection{Description of the Reactor System and its Operation}

An adequate description of the modified reactor system and its operation was provided in the Progress Report dated January 19,1994. The operation of the equipment during the past quarter has further confirmed the operability of the system. The manuscript of a paper covering the design and operation of the equipment has been prepared and submitted to Energy and Fuels. A copy of this manuscript entitled "A NOVEL LABORATORY SCALE SHORT CONTACT TIME REACTOR SYSTEM FOR STUDYING FUEL PROCESSES. 1. Apparatus and Preliminary Experiments" is attached.

In the past quarter, a detailed heat and momentum transfer analysis has been made of the preheater section to provide a basis for scaling the equipment, and adapting it to other particular fuel related needs. This work is described briefly in the experimental section of this progress report. It is also explained in greater detail in a manuscript submitted to Energy and Fuels entitled "A NOVEL LABORATORY SCALE REACTOR SYSTEM FOR STUDYING FUEL PROCESSES FROM THE INITIAL STAGES. 2. Detailed Momentum and Heat Transfer Analysis" which is also attached to this report.

\section{EXPERIMENTAL PROGRESS}

\subsection{Detailed Energy and Momentum Analysis of the Preheater System}

Fluid flow calculations have shown that the reactant(s) are introduced with gas pressure into the reactor through the preheater in 0.3 seconds. This has been substantiated experimentally. Since heat up time must be minimized to obtain accurate kinetics and to study the early stages of the liquefaction reaction, this of course means that all the heat required to bring the reaction mixture to approximately reaction temperature must be introduced in that short time interval. Heat transfer calculations show that very little heat can be transferred from the sand of the sand bath to the preheater in that short time. Essentially all of the heat required to heat the process stream therefore must be transferred from the sensible heat of the preheater and the reactor which are already at reaction temperature. Since the preheater contains the vast majority of the heat transfer surface, a heat transfer analysis of the preheater was necessary if the apparatus were to be optimized. Such an analysis was carried out and the results are covered in detail in the second attached manuscript. In brief, the temperature of the reaction mixture can be brought up to the reaction temperature within a few $\left(5-8^{\circ} \mathrm{C}\right)$ degrees in the time frame required. This has been confirmed experimentally in our equipment with $30 \mathrm{ml}$ of tetralin which closely 
approximates quantities and types of reaction mixtures we intend to use.

\subsection{Coal Liquefaction Studies}

2.2.1. Apnaratus and Coal Liquefaction Runs

The apparatus and method of operation for carrying out coal liquefaction runs were described in detail in the previous quarterly report dated January 19,1994. A summary of the coal liquefaction experiments made since that date are given in Table $\mathrm{I}$.

\subsubsection{Thermogravimetric Analysis of Coal}

The thermogravimetric analysis of coal was also briefly described in the previous report. A TGA and its corresponding differential curve (DTG) for a bituminous coal (Illinois \#6) run at atmospheric pressure in $\mathrm{N}_{2}$ and at a heating rate of $10^{\circ} \mathrm{C} / \mathrm{min}$ to $950^{\circ} \mathrm{C}$ are shown in Figure 1. TGA profiles of coal show several major characteristic parameters, such as VM (volatile matter), FC (fixed carbon) and ash. The FC only appears upon addition of oxygen which burns off the remaining carbonaceous material and leaves ash. In this quarter, an investigation of the effect of TGA variables has been made in an effort to optimize the use of this method of following the course of the liquefaction process. This has also necessitated the selection of a suitable workup procedure for the liquefaction products to be analyzed.

\subsubsection{Coal Liquefaction Product Workup Procedure and Determination of Liquefaction \\ Conversion}

During the liquefaction process in tetralin at low conversion, the mineral matter of the coal remains with the partially converted coal and is essentially insoluble in the tetralin. The coal liquids however are largely extracted into the tetralin solvent, although some remains with the coal residue. This provides a means of measuring the conversion of the coal by determining the ash content of the residue (by TGA) when it has been washed free of the coal liquids present in it and comparing it with a similarly prepared unreacted sample of the same coal. All the tetralin and tetralin-derived products must also be removed or an error in the conversion calculation will result.

The conversion can be calculated using Eq. 1:

$$
\text { Conversion }=\left(1-\frac{X_{0}}{X}\right) \times 100(w t z)
$$

where $\mathrm{X}_{0}$ is the ash content of the similarly treated but unreacted original coal and $\mathrm{X}$ is the ash content of the coal residue. When a solid catalyst is used in the liquefaction process, additional ash is formed in the coal residue which can be corrected for. A method for making this correction in studying coal liquefaction high temperature resids was developed previously, and is described in previous publications (1-3).

In a liquefaction experiment, the solid partially reacted coal is filtered from the tetralin and dissolved coal liquids, and must be washed on the filter to remove the residual 
coal liquids and tetralin. Our tests show that the tetralin cannot be used as the only wash solvent, as it is not completely removable from the solids by evaporation in a vacuum oven. Washing of the filter cake with tetrahydrofuran, a standard solvent often used in coal extraction, also does not remove all the tetralin, as shown by TGA experiments. The most satisfactory solvent we have found for washing the coal residue is methylene chloride. For this reason, we have adopted a workup procedure including methylene chloride treatment. The basis for this selection is the following experiments described below:

When coal is treated with tetralin at room temperature in the reactor followed by filtiation, the obtained filter cake was washed by tetralin and dried in a vacuum oven at $105^{\circ} \mathrm{C}$ for 48 hours. A DTG (the derivative of the TG curve) of this sample is shown in Figure 2. This shows a low temperature peak not present in unreacted coal, which is due to the tetralin that has not been removed. A tetrahydrofuran wash of the residue still shows the same tetralin peak (see Figure 2). However, a methylene chloride wash does remove the tetralin as shown by a DTG curve in Figure 2.

\subsubsection{Following the Coal Liquefaction Process by Means of TGA}

A typical TGA curve and its corresponding differential curve (DTG) for a bituminous coal (Illinois \#6) run at atmospheric pressure and heating rate of $10^{\circ} \mathrm{C} / \mathrm{min}$. is shown in Figure 1. It should be noted that this coal shows three characteristic DTG peaks in the VM portion. The processes involved in each of these peaks is not understood. However, the profiles are quite reproducible and depend on the conditions (heating rate, atmosphere etc.) under which the analysis is run. These profiles change in the partially reacted coal during the course of the liquefaction reaction.

Interesting insights into coal structure and the coal liquefaction process can be obtained by running TG analyses in nitrogen and in hydrogen at various heating rate on coal and partially reacted coal residues produced at various liquefaction reaction times. Figures 3,4 , and 5 show plots of VM for unreacted Illinois \#6, Utah Blind Canyon bituminous coals and Wyodak Black Thunder subbituminous coal, respectively. They were determined by TGA in nitrogen and in hydrogen at heating rates varying from $10^{\circ} \mathrm{C} / \mathrm{min}$ to $200^{\circ} \mathrm{C} / \mathrm{min}$. For the bituminous coals, strong effects of heating rate on the VM measurements in the two gases are observed. In the bituminous coals, the VM yields in nitrogen gas rapidly increased with heating rate and then levelled off. This is tentatively attributed to an unstable component in the coal or its pyrolysis liquid when the volatile product is only slowly removed from the coal in nitrogen. This may tesult in free radical retrograde reactions and low volatile yields. The VM yields in hydrogen gas actually decreased somewhat with heating rate, although the overall volatile yields were higher in hydrogen than in nitrogen. The presence of hydrogen in the TG pyrolysis apparently stabilizes or quenches the free radicals and suppresses the retrograde reactions. The lower VM yield with higher heating rate in hydrogen may be due to a mass transfer limitation of the hydrogen into the coal and coal liquid which may be more favorable at the low heating rate.

The behavior of the subbituminous coal is somewhat different than the bituminous 
coals. In nitrogen, VM increases only very slowly with heating rate, but in hydrogen, VM is substantially increased. The low VM yield in nitrogen even at high heating rate, may also be a mass transfer effect. In the bituminous coals there is melting during the heating process which may facilitate volatilization of the VM. In the subbituminous coal which does not melt, volatilization may be impeded, and retrograde reactions can occur in nitrogen.

Figure 6 shows DTG vs temperature curves for partially converted coal liquefaction residues of Illinois \#6 coal after liquefaction in tetralin at $390^{\circ} \mathrm{C}$ under 1000 psig nitrogen at selected contact times. The gradual disappearance of the two smaller peaks clearly indicate that some chemical changes in the solid coal are taking place before the coal actually becomes liquid. Such chemical changes during the early stages of liquefaction is supported by previously observed changes in the total oxygen and hydroxyl content of the partially reacted coal (4-6). In addition, the sensitivities of the residues to heating rate and to atmospheres of nitrogen and hydrogen is significantly changed as is shown in Figure 7 for a liquefaction sample of Illinois $\# 6$ taken after 30 seconds. The profound changes shown in that short time suggests that short exposure to donor solvent can significantly change the character of the coal before much actual liquefaction has taken place. This change may merely be the removal of a very unstable volatile fraction, or actual stabilization by hydrogen transfer from the donor solvent.

These experiments also suggest the presence of an unstable fraction in the unreacted coal or coal liquid which contributes to coke formation unless rapid and adequate contact with hydrogen is attained. This is consistent with previous pyrolysis studies.

2.26 Conversion of Illinois \#6 vs time during coal Liquefaction.

Figure 8 show a plot of liquefaction conversion vs time for Illinois $\# 6$ at $390^{\circ} \mathrm{C}$. This curve suggests rapid extraction of the easily soluble material (a mobile phase?) in the first few seconds of the liquefaction. The conversion curve after the initial rapid extraction suggests multistep reactions with the more easily broken bonds cleaving first, followed by the stronger bonds. This is consistent with current liquefaction experience at Wilsonville and other laboratories.

\section{FUTURE PROGRAM}

We plan to investigate the various variables involved in coal liquefaction at short reaction times, and to continue the development of analytical methods for following the liquefaction reaction including methods for determination of the oxygen components.

\section{SUMMARY AND CONCLUSIONS}

A momentum and heat transfer analysis of the preheater system confirms the experimental observation that reaction mixtures can be transferred into the reactor through the preheater in less than one second, and at a temperature close to the target reaction temperature.

A workup protocol has been devised which is being used along with TGA to 
determine liquefaction conversion without the error due to the presence of coal liquids or tetralin.

Interesting differences have been observed in the three coals studied by running TGA at different heating rates and in nitrogen and hydrogen atmospheres. These experiments suggest the presence of an unstable component in the coal or coal derived liquid which is rapidly removed or stabilized by hydrogen or by very short treatment with donor solvent under liquefaction conditions.

\section{REFERENCES}

1. Huang, H.; Calkins, W.H.; Klein, M.T. The Use of a Novel Short Contact Time Batch Reactor and Thermogravimetric Analysis to Follow the Conversion of CoalDerived Resids during Hydroprocessing. Submitted in $I \& E C$.

2. Huang, H.; Calkins, W.H.; Klein, M.T. The Use of Thermogravimetric Analysis to Follow the Conversion of Coal-Derived Resids in the Resid Recycling Process. ACS Fuel Chem Div. Preprints 1994, 39 (2), 581.

3. Klein, M.T.; Calkins, W.H.; Huang, H. Coal Liquefaction Process Streams Characterization and Evaluation: The Preliminary Evaluation of the Kinetics of Coal Liquefaction Distillation Resid Conversion. 1994, DOE/PC 89883-89

4. Huang, H.; Provine, W.D.; Jung, B.; Jacintha, M.A.; Rethwisch, D.G.; Calkins, W.H.; Klein, M.T.;Dybowski, C.R.; Scouten, C.G. Short Time Reactor System for Studying the Initial Stages of Coal Liquefaction. Proceedings of the International Conference on Coal Science, 1993, Ed. K.H. Michaelian, Vol. I, 266.

5. Jung, B.; Provine, W.D.; Calkins, W.H.; Klein, M.T.; Scouten, C.G. Changes in Organic Oxygen Contents of Illinois \#6 Coal during Coal Liquefaction. ACS Fuel Chem Div. Preprints 1992, 37 (2), 670.

6. Provine, W.D.;Jung, B.; Jacintha, M.A.;Rethwisch, D.G.; Huang, He; Calkins, W.H.; Klein, M.T.; Scouten, C.G.; Dybowski, C.R. A Kinetic Investigation of Coal Liquefaction at Short Reaction Times. Catalysis Today, 1994, Ed. D.B. Dadyburjor and J.W. Zondlo, Vol. 19, No. 3, 409.

- Preprints - resnoved 
Table I Illinois $\$ 6$ Coal Liquefaction Runs

\begin{tabular}{lcccc}
\hline Sample & $\begin{array}{c}\text { Contact time } \\
\text { mis }\end{array}$ & $\begin{array}{c}\text { T/C } \\
(w t)\end{array}$ & $\begin{array}{c}\text { Temperature } \\
{ }^{\circ} \mathrm{C}\end{array}$ & $\begin{array}{c}\text { Recovery } \\
w t \%\end{array}$ \\
DOE001 & 15.00 & 8 & 15 & $78 \%$ \\
DOE012 & 0.17 & 8 & 390 & $86 \%$ \\
DOE015 & 0.50 & 8 & 384 & $92 \%$ \\
DOE016 & 0.75 & 8 & 385 & $89 \%$ \\
DOE017 & 1.00 & 8 & 386 & $88 \%$ \\
DOE021 & 5.00 & 8 & 387 & $87 \%$ \\
DOE013 & 10.00 & 8 & 390 & $82 \%$ \\
DOE009 & 30.00 & 8 & 390 & $85 \%$ \\
DOE010 & 60.00 & 8 & 390 & $81 \%$ \\
& & & & \\
\hline
\end{tabular}


List of the Figures

Figure 1. A TG scan on the Illinois \#6 coal

Figure 2. Disappearance of the incomplete peak on the low temperature side of the principal VM peak due to the presence of residual tertalin in the control sample and the reacted solid residue by methylene chloride washing

Figure 3. Effect of heating rate on the VM yields of raw Illinois \#6 bituminous coal determined by $\mathrm{TG}$ pyrolysis in $\mathrm{N}_{2}$ and in $\mathrm{H}_{2}$

Figure 4. Effect of heating rate on the VM yields of raw Utah Blind Canyon bituminous coal determined by TG pyrolysis in $\mathrm{N}_{2}$ and in $\mathrm{H}_{2}$

Figure 5. Effect of heating rate on the VM yields of raw Wyodak Black Thunder subbituminous coal determined by TG pyrolysis in $\mathrm{N}_{2}$ and in $\mathrm{H}_{2}$

Figure 6. DTG profiles for residues of the Illinois \#6 coal after liquefaction in tetralin at the selected contact times (TG scan at $10^{\circ} \mathrm{C} / \mathrm{min}$ in $\mathrm{N}_{2}$; liquefaction run at $390{ }^{\circ} \mathrm{C}$ under 1000 psig $\mathrm{N}_{2}$ with $\mathrm{T}: \mathrm{C}=8: 1$ )

Figure 7. Effect of heating rate on VM yields of Illinois \#6 coal liquefaction residue determined by TG pyrolysis in $\mathrm{N}_{2}$ and in $\mathrm{H}_{2}$

Figure 8. Kinetics of the Illinois \#6 coal liquefaction in tetralin $\left(1000\right.$ psig $\mathrm{N}_{2}$ gas; $390{ }^{\circ} \mathrm{C}$; $\mathrm{T}: \mathrm{C}=8: 1)$ 


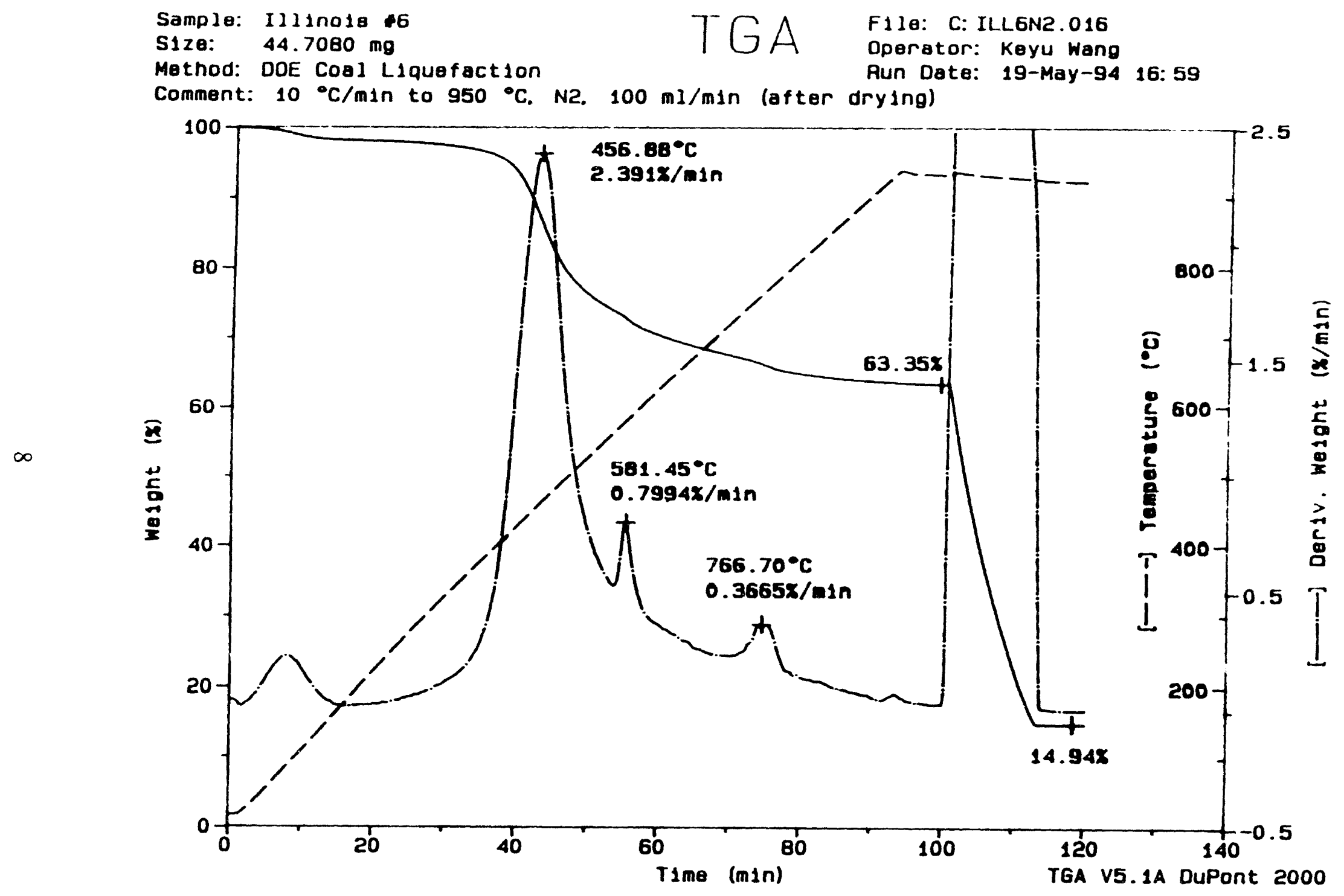

Figure 1. A TG scan on the Illinois 6 coal 


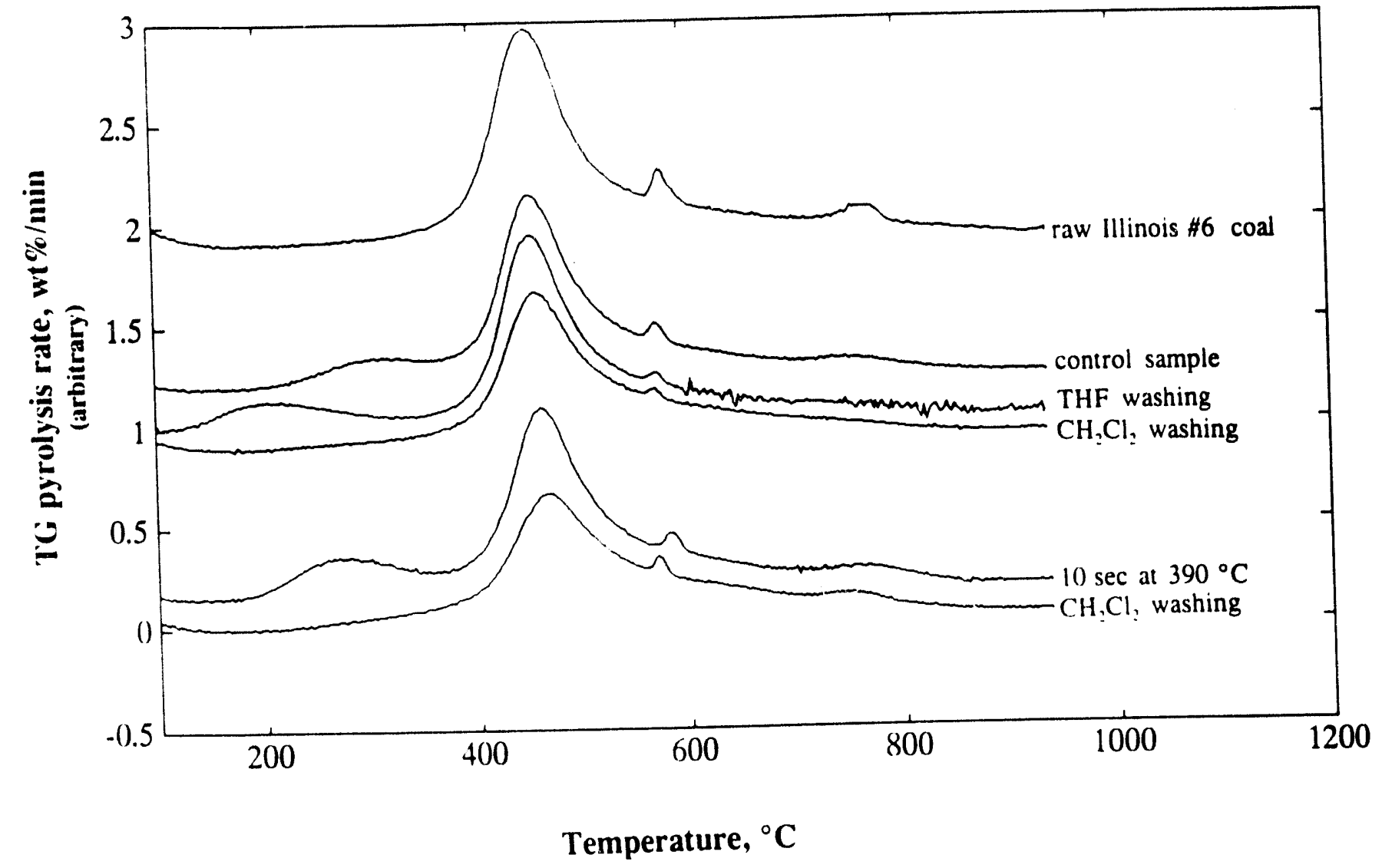

Figure 2. Disappearance of the incomplete peak on the low temperature side of the principal VM peak due to the presence of residual tertalin in the control sample and the reacted solid residue by methylene chloride washing 


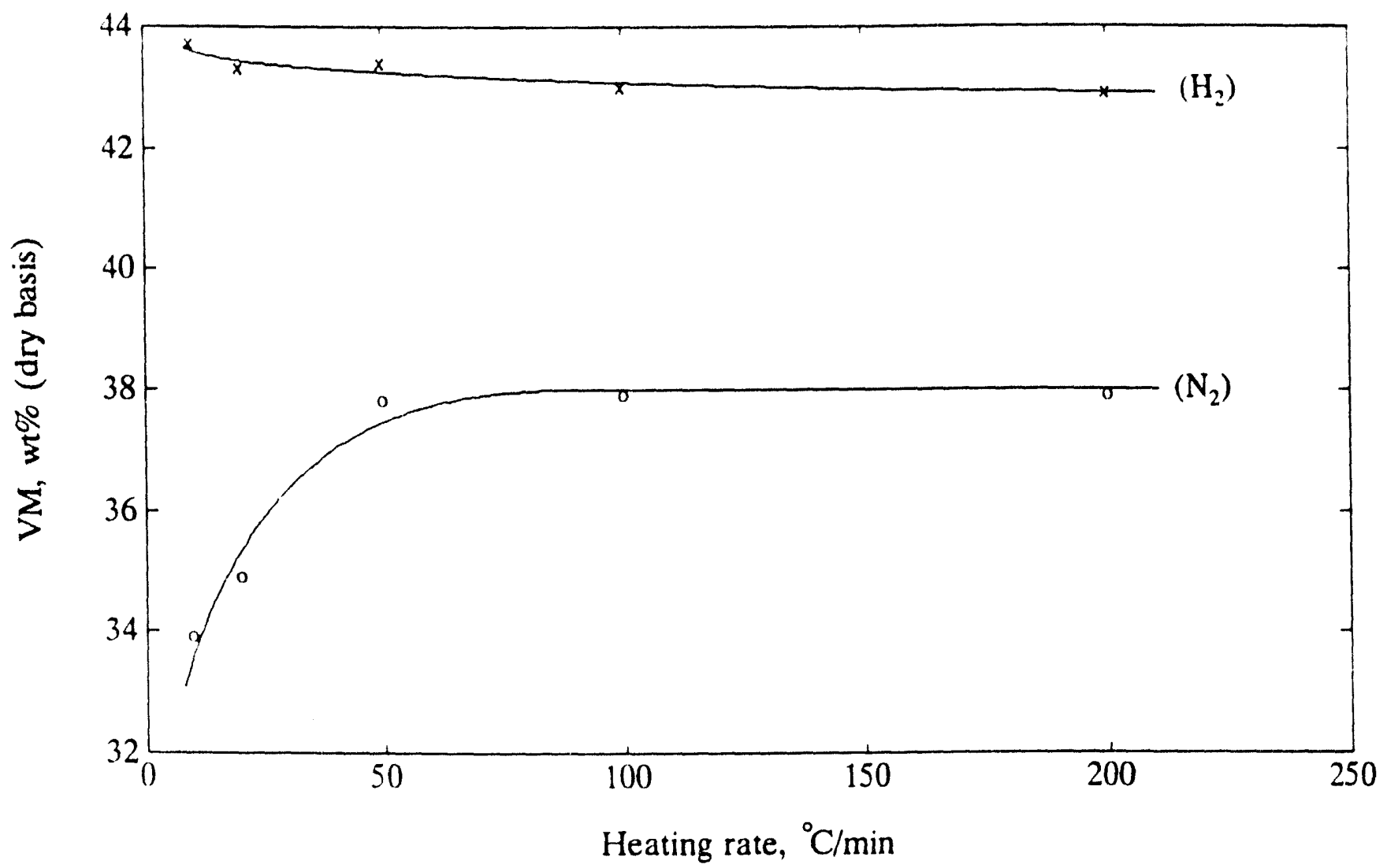

Figure 3. Effect of heating rate on the VM yields of raw Illinois \#6 bituminous coal determined by TG pyrolysis in $\mathrm{N}_{2}$ and in $\mathrm{H}_{2}$ 


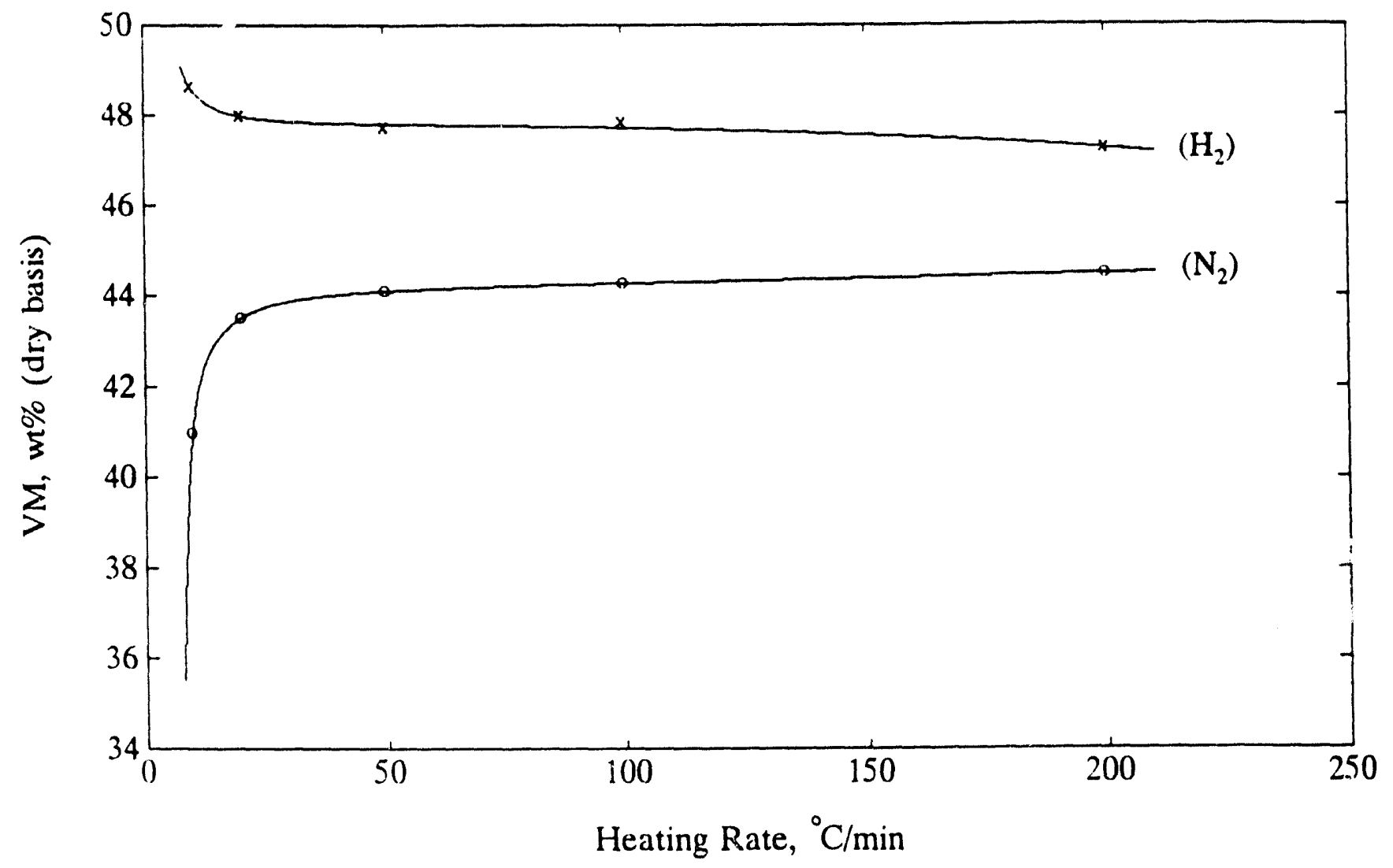

Figure 4. Effect of heating rate on the VM yields of raw Utah Blind Canyon bituminous coal determined by TG pyrolysis in $\mathrm{N}_{2}$ and in $\mathrm{H}_{2}$ 


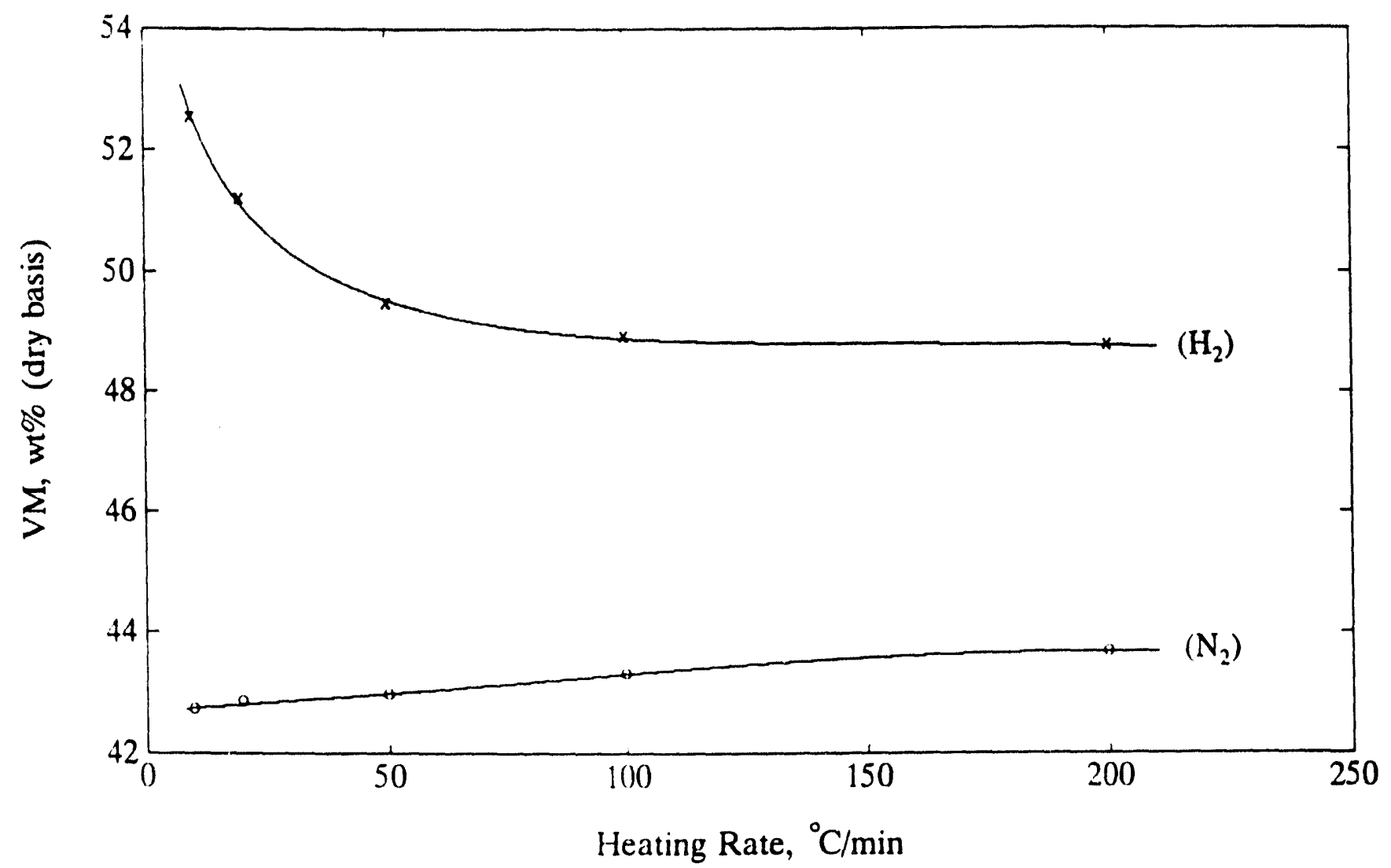

Figure 5. Effect of heating rate on the VM yields of raw Wyodak Black Thunder subbituminous coal determined by TG pyrolysis in $\mathrm{N}_{2}$ and in $\mathrm{H}_{2}$ 


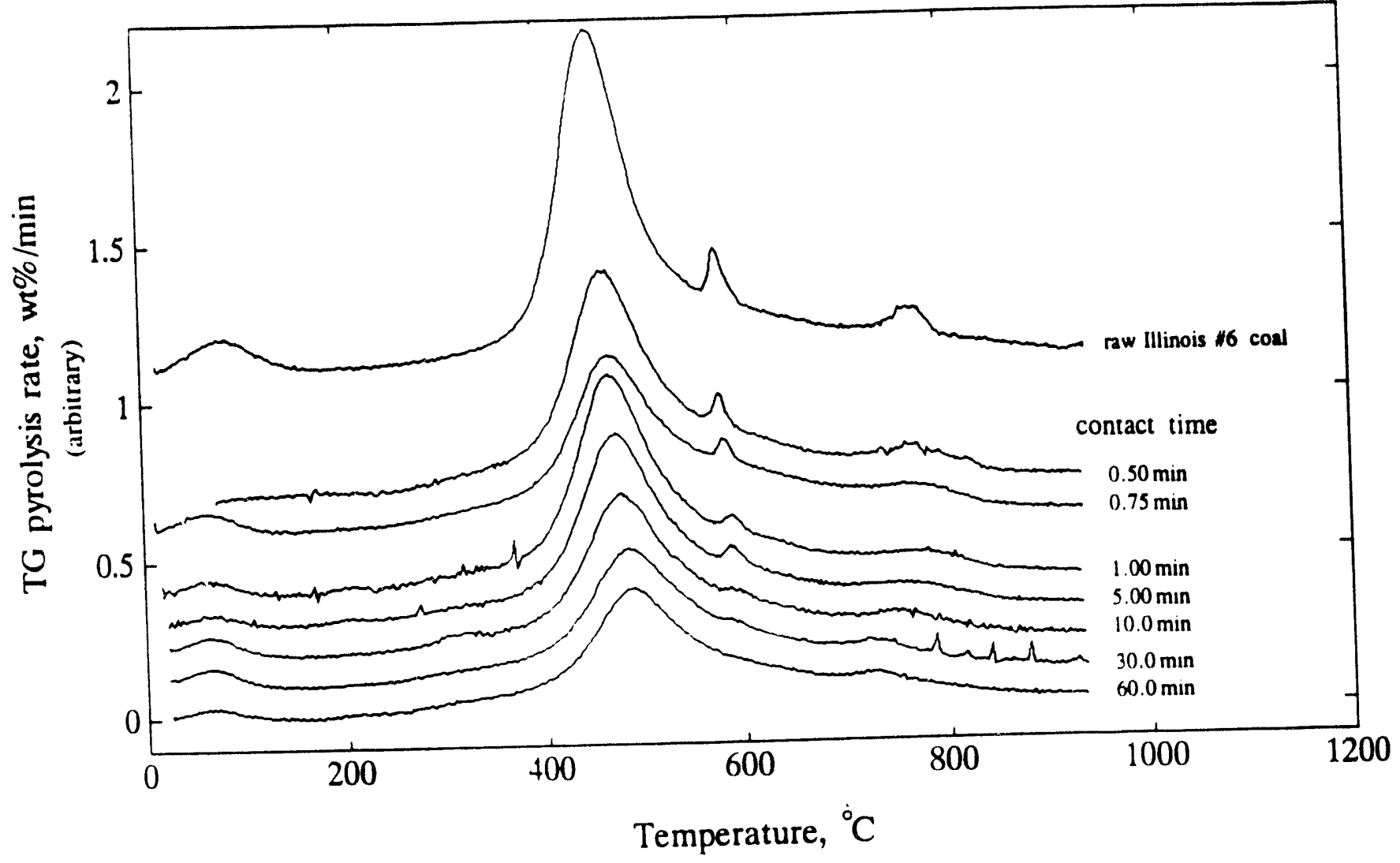

Figure 6. DTG profiles for residues of the Illinois \#6 coal after liquefaction in tetralin at the selected contact times (TG scan at $10{ }^{\circ} \mathrm{C} / \mathrm{min}$ in $\mathrm{N}_{2}$; liquefaction run at $390{ }^{\circ} \mathrm{C}$ under 1000 psig $\mathrm{N}_{2}$ with $\mathrm{T}: \mathrm{C}=8: 1$ ) 


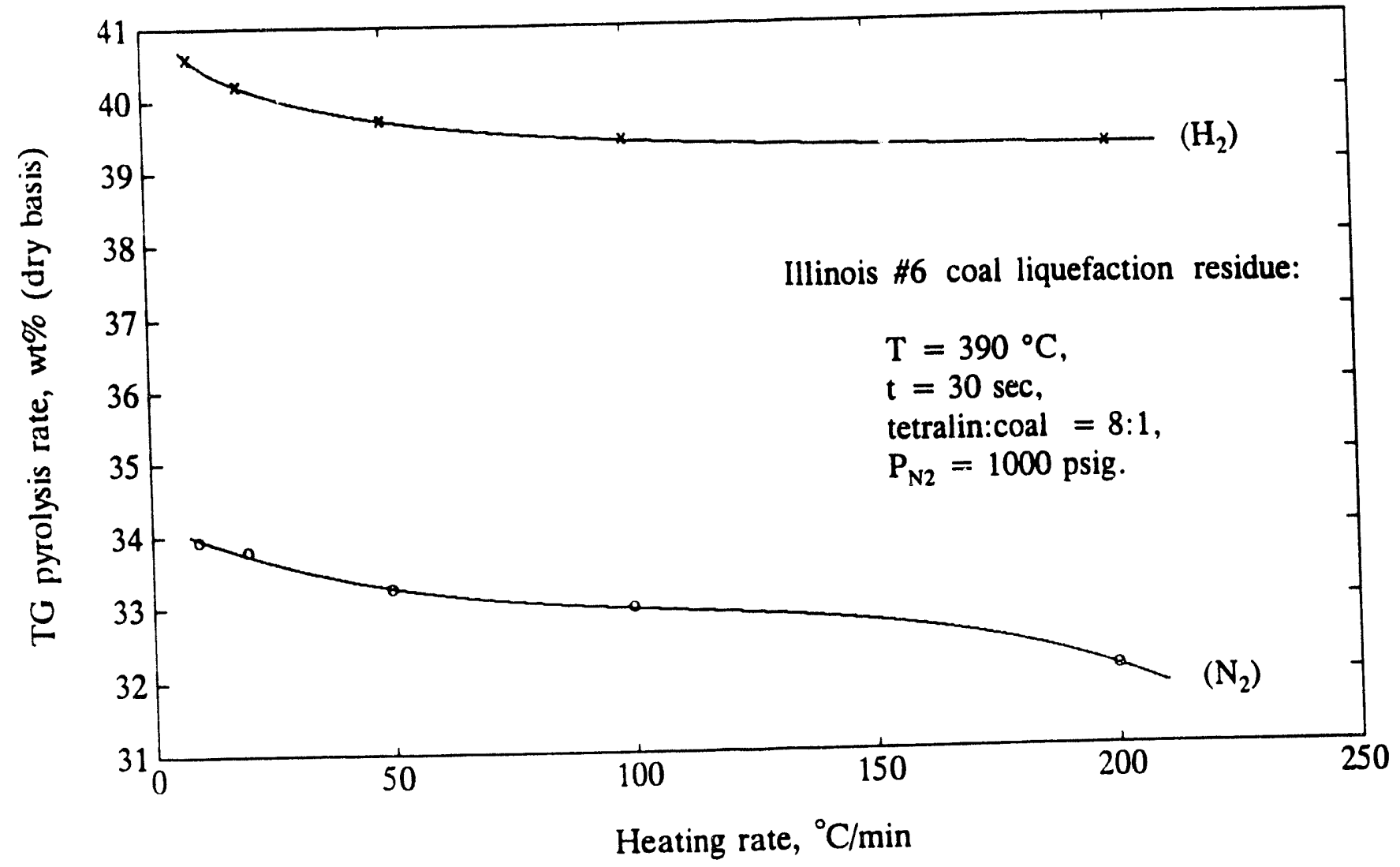

Figure 7. Effect of heating rate on $\mathrm{VM}$ yields of Illinois $\# 6$ coal liquefaction residue determined by TG pyrolysis in $\mathrm{N}_{2}$ and in $\mathrm{H}_{2}$ 


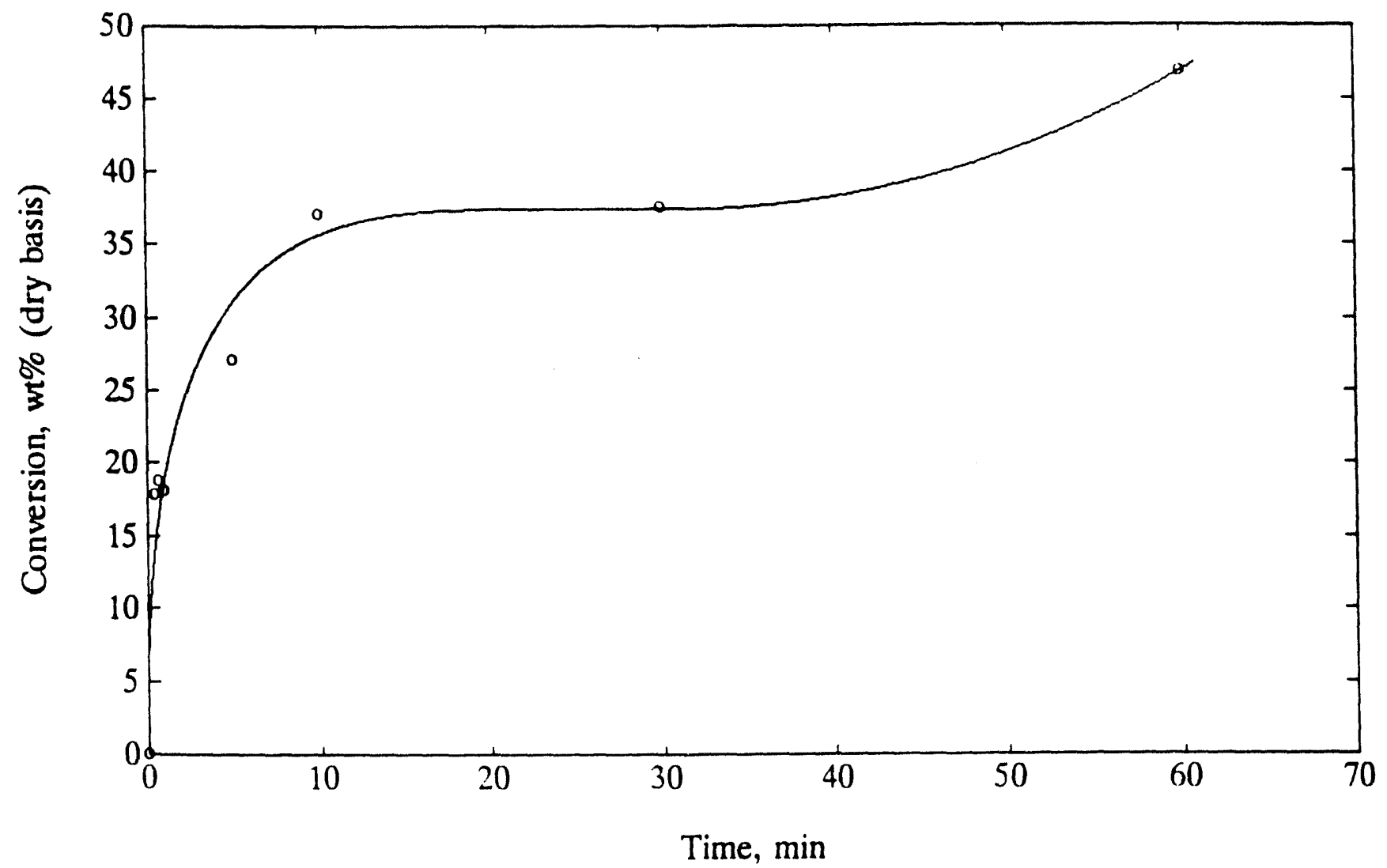

Figure 8. Kinetics of the Illinois $\# 6$ coal liquefaction in tetralin (1000 psig $\mathrm{N}_{2}$ gas; $390{ }^{\circ} \mathrm{C}$; $\mathrm{T}: \mathrm{C}=8: 1)$ 

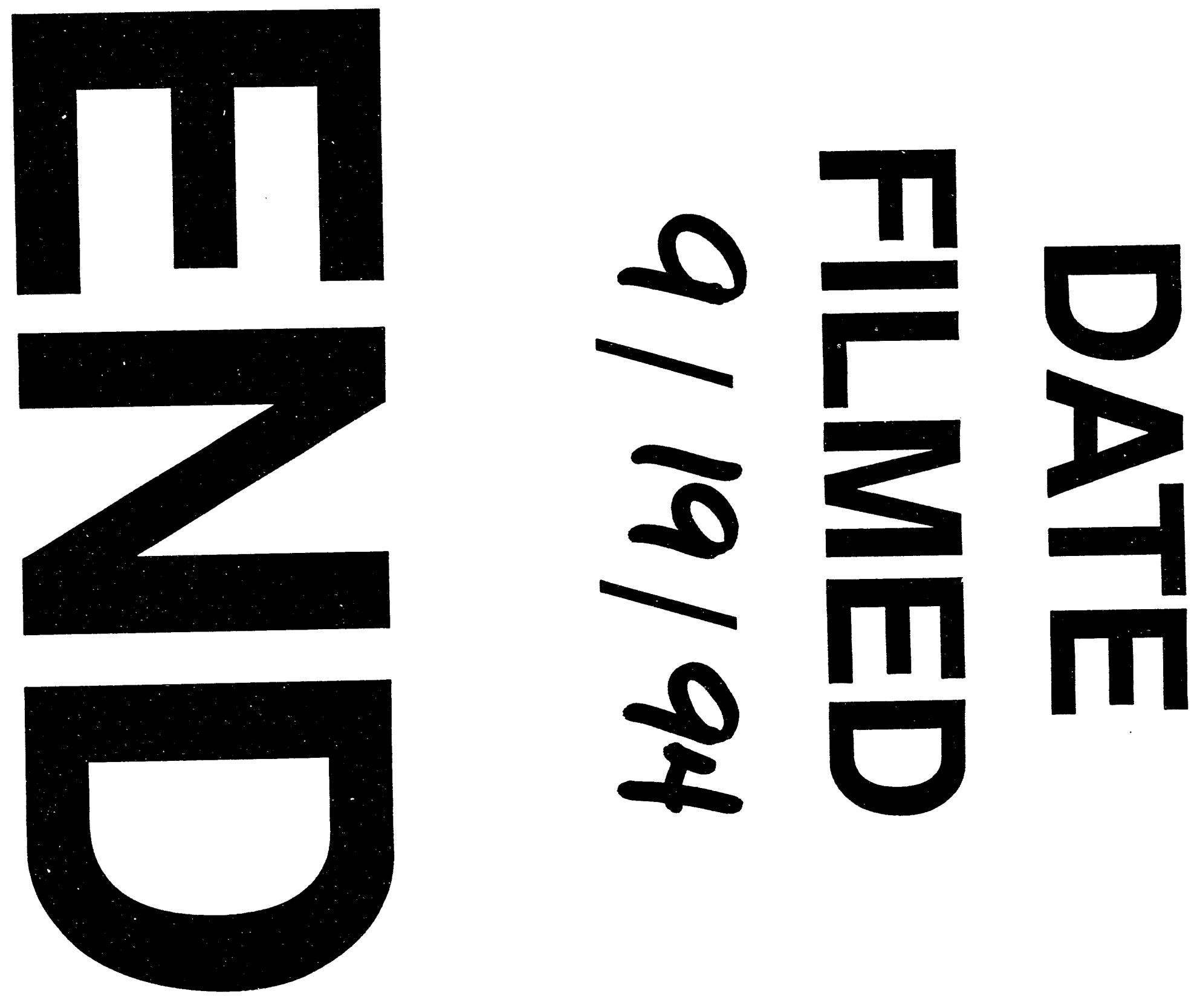


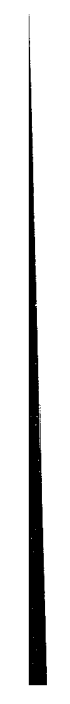

